\title{
Prototipe Frekuensi Meter Rentang Ukur (10 2000) Hz Terkalibrasi ke Standar Primer Frekuensi
}

\author{
Prototype of Meter Frequency Range (10 2000) Hz Calibrated to \\ Primary Standard Frequency
}

Purwowibowo, Jalu Ahmad Prakosa

Pusat Penelitian Metrologi LIPI

Kompleks Puspiptek Serpong, Tangerang, Banten 15314

Email: purwowibowo@kim.lipi.go.id, jaluahmad@gmail.com

\begin{abstract}
The frequency measurement has very important role in the field of signal measurement system mainly for acquisition data of pulse signal on the turbine flow meter. To meet the accurate measurement and become independent technology, a local product of calibrated frequency meter is needed. The purpose of this research is to create a prototype of calibrated frequency meter until range of $2000 \mathrm{~Hz}$ to guarantee the truth measurement internationally. Microcontroller of Arduino Uno board with 16-bit counter ability is used to calculate the frequency. The measurement result is displayed in real time by serial communication and on the Liquid Crystal Display. That prototype of frequency meter has been calibrated using standard of DS340 that is traceable to SI units through primary standard of frequency using cesium at Research Center for Metrology LIPI. The results of calibration and measurement on the measuring range of $(10 \sim 2000) \mathrm{Hz}$ obtained that the prototype of frequency meter has the maximum possible error of $0.7 \mathrm{~Hz}$. The measurement traceability of prototype of frequency meter with the resolution of $0.1 \mathrm{~Hz}$ and the relative accuracy of $0.03 \%$ full scale has been successfully built .
\end{abstract}

Keywords: Frequency meter, microcontroller, calibration, traceability, cesium standard

\begin{abstract}
Abstrak
Pengukuran besaran frekuensi sangat penting peranannya dalam bidang sistem pengukuran sinyal terutama untuk akuisisi data sinyal pulsa pada pengukur aliran jenis turbin. Untuk memenuhi kebutuhan pengukuran yang akurat dan menjadi mandiri secara teknologi diperlukan produk frekuensi meter lokal yang terkalibrasi. Tujuan penelitian ini adalah membuat prototipe frekuensi meter sampai rentang ukur $2000 \mathrm{~Hz}$ yang terkalibrasi sehingga terjamin nilai kebenaran pengukurannya secara internasional. Digunakan mikrokontroler board Arduino Uno dengan kemampuan pencacah 16 bit untuk menghitung frekuensi. Hasil pengukuran ditampilkan secara real time komunikasi serial serta pada Liquid Crystal Display (LCD). Telah dilakukan kalibrasi prototipe frekuensi meter tersebut menggunakan standar DS340 yang telah tertelusur ke satuan SI melalui standar primer frekuensi cesium Puslit Metrologi LIPI. Dari hasil kalibrasi dan pengukuran pada rentang ukur $(10$ 2000) $\mathrm{Hz}$ didapat bahwa prototipe frekuensi meter ini memiliki kemungkinan error terbesar sebanyak $0,7 \mathrm{~Hz}$. Telah berhasil dibangun ketertelusuran pengukuran prototipe frekuensi meter tersebut dengan resolusi $0,1 \mathrm{~Hz}$ dan akurasi $0,03 \%$ relatif skala penuh.
\end{abstract}

Kata kunci: Frekuensi meter, mikrokontroler, kalibrasi, ketertelusuran, standar cesium.

\section{Pendahuluan}

Pengukuran besaran frekuensi sangat penting peranannya dalam aplikasi pengukuran sinyal. Berbagai teknologi dan aplikasi bergantung pada ketepatan pengukuran waktu dan frekuensi termasuk pasar keuangan, jaringan telepon kabel dan nirkabel, stasiun radio broadband, jaringan listrik, navigasi sistem radio, dan aplikasi-GPS [1]

Received: 27 Februari 2015; Revised: 7 Mei 2015; Accepted: 8 Mei 2015 ; Published online: 10 Juli 2015

(C)2015 INKOM 2015/15-NO412 terutama pengukuran gerakan rotasi, tachometer maupun akuisisi data sinyal pulsa pada pengukur aliran jenis turbin [2]. Pengukuran frekuensi yang akurat dan presisi dibutuhkan untuk menjamin kebenaran hasil pengukurannya.

Untuk menjamin keakuratan dan kepresisian pengukuran besaran perlu dikalibrasi dengan standar yang tertelusur ke satuan SI. Standar primer frekuensi merupakan standar tertinggi yang diturunkan langsung dari besaran pokoknya yaitu cacah berulang per satuan waktu. Satuan internasional waktu sekon didefinisikan sebagai durasi dari 9192631770 periode radiasi pada 
transisi antara dua level hyperfine pada ground state dari atom caesium-133 [3].

Di Indonesia produk frekuensi meter masih didominasi oleh produk luar negeri sedangkan kebutuhan frekuensi meter cukup besar di Indonesia sehingga diperlukan usaha penguasaan teknologi frekuensi meter secara mandiri. Teknologi mikrokontroler board Arduino Uno yang memiliki fasilitas osilator $16 \mathrm{MHz}$ dan pencacah 16 bit dapat dimanfaatkan untuk membuat prototipe frekuensi meter [4]. Laboratorium waktu dan frekuensi Pusat Penelitian (Puslit) Metrologi LIPI memiliki fasilitas standar primer frekuensi cesium tipe HP5071A untuk menguji dan mengkalibrasi prototipe frekuensi meter tersebut. Rentang frekuensi yang dirancang sampai $2000 \mathrm{~Hz}$ agar menyesuaikan kebutuhan data akuisisi untuk sinyal pulsa pada pengukur aliran jenis turbin. Pada pengukur aliran jenis turbin yang banyak digunakan pada industri penerbangan dan energi memiliki diameter dibawah 2,5 inci dan menggunakan laju aliran fluida sampai 1400 liter/menit sehingga mengeluarkan sinyal pulsa sampai frekuensi 2000 $\mathrm{Hz}$ [2]. Tujuan penelitian ini adalah membuat prototipe frekuensi meter sampai rentang ukur $2000 \mathrm{~Hz}$ yang terkalibrasi sehingga terjamin nilai kebenaran pengukurannya secara internasional. Tulisan ini melaporkan hasil penelitian tentang rancang bangun prototipe frekuensi meter yang terkalibrasi standar primer waktu dan frekuensi cesium.

\section{Tinjauan Pustaka}

Pada bab ini menjelaskan definisi besaran frekuensi yang akan diukur, mikrokontroler yang memiliki fasilitas counter - timer yang dapat dimanfaatkan sebagai pengukur frekuensi serta kalibrasi frekuensi meter dan standar yang digunakan.

\subsection{Frekuensi}

Frekuensi adalah suatu peristiwa berulang. Jika $\mathrm{T}$ adalah waktu dari peristiwa berulang $\mathrm{n}$, maka frekuensi $\mathrm{f}=\mathrm{n} / \mathrm{T}$. Oleh karena itu frekuensi merupakan besaran turunan dari besaran waktu. Satuan waktu yaitu sekon merupakan suatu bagian 1/86 400 dari rata-rata 1 hari siklus matahari. Definisi yang tepat dari rata-rata 1 hari siklus matahari akibat rotasi bumi masih merupakan pertanyaan tersisa bagi astronom. Namun dalam pengukuran sesungguhnya masih menunjukkan penyimpangan dalam rotasi bumi sehingga membuat definisi tersebut kurang memuaskan. Dalam rangka untuk menentukan satuan waktu yang lebih tepat, Konferensi Umum mengenai Berat dan Ukuran - Conférence Générale des Poids et Mesures (CGPM) ke-11 (1960, Resolusi 9, CR, 86) mengadopsi definisi yang diberikan oleh International Astronomical Union tahun 1900 yaitu standar atom waktu berdasarkan pada transisi antara dua tingkat energi atom atau molekul bisa diwujudkan dan direproduksi lebih akurat sebagai definisi satuan waktu yang lebih baik. Ilmu pengetahuan dan teknologi memerlukan definisi satuan waktu yang lebih tepat, CGPM ke-13 (1967-1968, Resolusi 1; CR, 103 dan Metrologia 1968, 4, 43) menggantikan definisi Sekon sebagai berikut:

"Sekon didefinisikan sebagai durasi dari 9 192631770 periode radiasi pada transisi antara dua level hyperfine pada ground state dari atom cesium-133"[3].

Hal tersebut menunjukkan bahwa hyperfine membelah dalam keadaan dasar dari atom cesium133 tepatnya 9192631770 hertz, v (HFS Cs) $=9$ 192631770 Hz. Pada pertemuan tahun 1997, Komite Internasional untuk berat dan ukuranComité international des poids et mesures (CIPM) menegaskan bahwa definisi ini mengacu pada keadaan atom cesium saat istirahat pada suhu 0 Kelvin. Catatan ini dimaksudkan untuk mempertegas bahwa definisi sekon pada SI didasarkan pada atom cesium yang terganggu oleh radiasi benda hitam yaitu dalam lingkungan dengan suhu termodinamika pada 0 Kelvin. Besaran temperatur mempengaruhi pengukuran waktu. Frekuensi pada semua standar primer frekuensi harus dikoreksi terhadap pergeseran akibat radiasi sekitar, seperti dinyatakan pada pertemuan Komite Konsultatif untuk waktu dan frekuensi pada tahun 1999 [3]. Dalam Sistem Satuan Internasional (SI) periode dinyatakan dalam satuan sekon (s), maka frekuensi harus dinyatakan dalam seperdetik dengan satuan hertz $(\mathrm{Hz})$. Frekuensi sinyal listrik sering diukur dalam satuan kilohertz $(\mathrm{kHz})$ atau megahertz $(\mathrm{MHz})$. Untuk aplikasi akuisisi data sinyal pulsa pada pengukur aliran jenis turbin digunakan frekuensi sampai rentang ukur $2000 \mathrm{~Hz}$ atau $2 \mathrm{kHz}$.

\subsection{Mirokontroler}

Mikrokontroler banyak dimanfaatkan sebagai intrumen pada frekuensi meter digital. Teknologi pemrograman mikrokontroler berbasis open source Arduino sangat populer dewasa ini yang juga sangat membantu kegiatan penelitian karena menghindarkan dari masalah lisensi dan pembiayaan. Pada penelitian ini dipilih papan Arduino Uno berkaitan optimalisasi kebutuhan spesifikasi mikrokontroler dan besar harganya. 
Arduino Uno merupakan salah satu jenis board berbasis mikrokontroler yang dapat diprogram menggunakan Arduino, yaitu software open source uploader mikrokontroler yang tengah populer dewasa ini. "Uno" berarti satu di Italia dan diberi nama untuk menandai peluncuran Arduino1.0. Board ini terdiri dari mikrokontroler ATmega168 atau ATmega328 yang memiliki 14 digital input / output pin (dimana 6 dapat digunakan sebagai output PWM), 6 input analog sebagai Analog to Digital Converter (ADC) 10 bit, $16 \mathrm{MHz}$ osilator kristal, 2 buah timer/counter 8 bit dan sebuah timer/counter 16 bit, koneksi USB, jack listrik, header ICSP, dan tombol reset dimana ini berisi semua yang diperlukan untuk mendukung mikrokontroler, mudah dihubungkan ke komputer karena menggunakan kabel USB atau power dengan adaptor AC-DC atau baterai untuk menjalankannya[4]. Berikut ini Gambar 1 tampilan Arduino Uno :

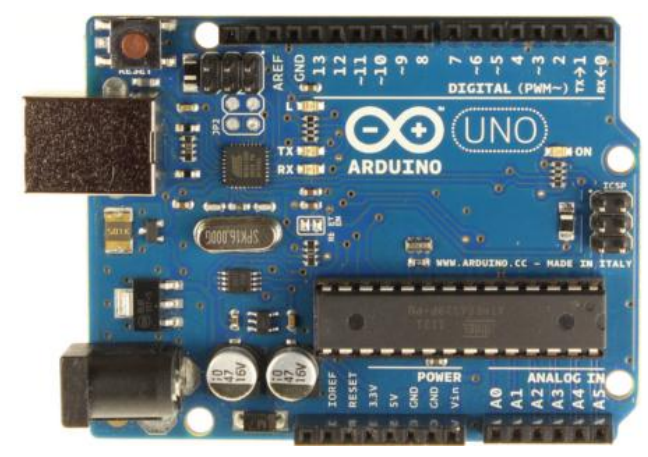

Gambar 1. Arduino Uno

Perancangan rangkaian kendali ini menggunakan Arduino Uno dengan mikrokontroler ATmega328 dimana konfigurasi dan pemetaan pinnya yang ditampilkan pada Gambar 2 di bawah ini,[5]:

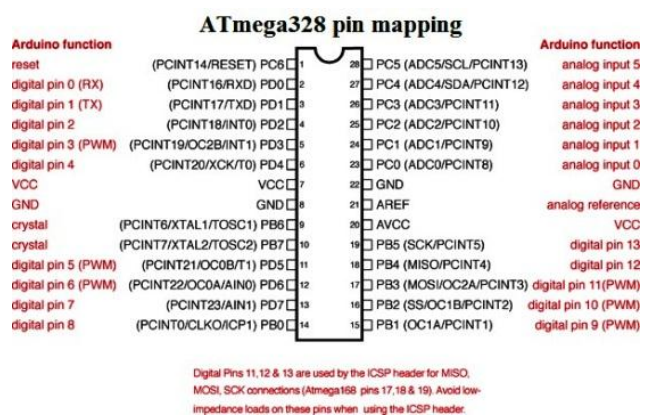

Gambar 2. Konfigurasi dan pemetaan pin mikrokontroler ATmega328[4]
Fasilitas pencacah 16 bit atau 65536 ruang cacahan pada timer/counter 1 (pin 5 digital) dan clock $16 \mathrm{MHz}$ dapat dimanfaatkan untuk membuat frekuensi meter.

\subsection{Kalibrasi dan Standar Frekuensi Meter}

Frekuensi rata-rata dalam interval waktu tertentu dapat diukur sangat tepat. Interval waktu adalah salah satu dari empat standar dasar pengukuran (yang lain adalah panjang, massa, dan suhu). Dari keempat standar dasar, interval waktu ( frekuensi) merupakan standar yang memiliki resolusi dan ketidakpastian yang paling kecil. Di beberapa bidang metrologi, satu bagian per juta $\left(1 \times 10^{-6}\right)$ dianggap cukup representatif. Tapi dalam metrologi frekuensi, pengukuran dari satu bagian per miliar $\left(1 \times 10^{-9}\right)$ bahkan satu bagian per triliun $\left(1 \times 10^{-12}\right)$ merupakan hal yang biasa [6]. Perangkat yang menghasilkan frekuensi sebagai nilai rujukan dapat disebut juga standar frekuensi. Dalam perangkat ini harus dikalibrasi sehingga tetap dalam toleransi yang dipersyaratkan oleh pengguna aplikasi [7]. Dalam menganalisa kelayakan akurasi modul frekuensi meter turbin flowmeter dapat digunakan standar frekuensi DS340 yang telah tertelusur ke standar primer frekuensi cesium tipe HP-5071A.

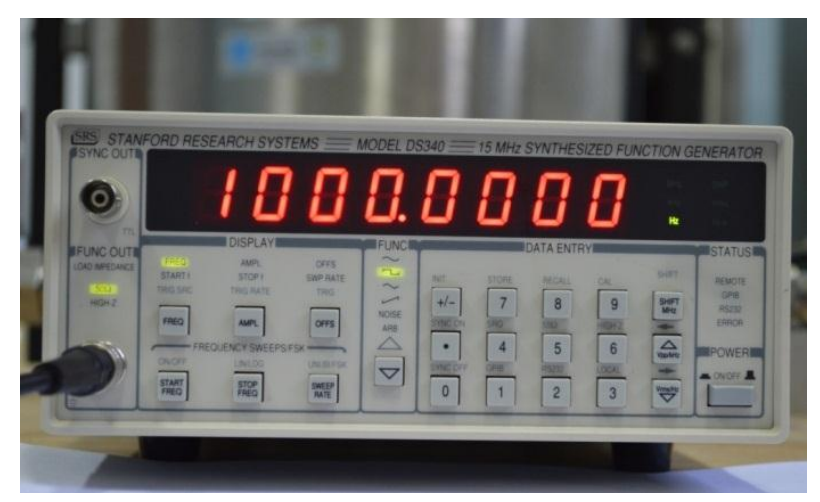

Gambar 3. Standar frekuensi DS340 di Laboratorium waktu dan frekuensi Puslit Metrologi LIPI

DS340 memiliki fitur yang lengkap dengan generator sampai frekuensi $15 \mathrm{MHz}$ yang menggunakan arsitektur Direct Digital Synthesis inovatif (DDS) sehingga ideal untuk berbagai macam test dan aplikasi pengukuran frekuensi. Alat ini dapat menghasilkan banyak bentuk gelombang standar seperti sinus, kotak, lereng, segitiga dan noise dengan resolusi frekuensi yang sangat baik yaitu sampai $1 \mu \mathrm{Hz}$. Standar DS340 memiliki $10 \mathrm{MHz}$ gaussian white-noise generator. Alat ini juga menghasilkan bentuk gelombang 


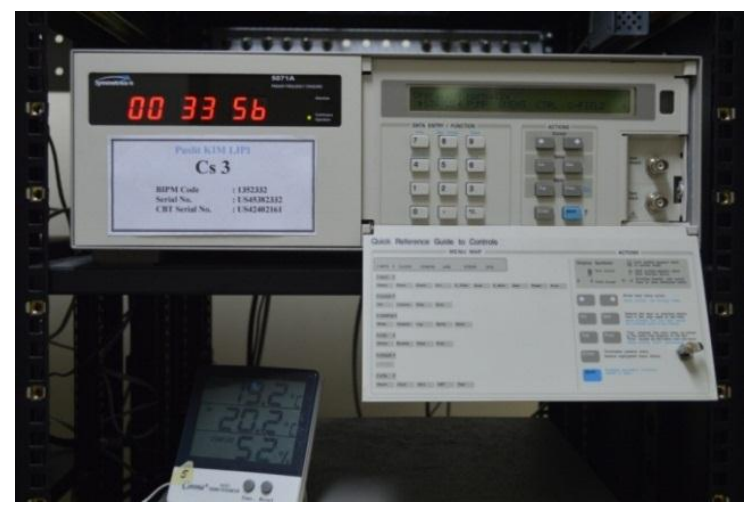

Gambar 4. Standar primer frekuensi HP-5071A di Puslit Metrologi LIPI

arbitrary dengan kecepatan update yang cepat yaitu 40 Msamples / s. Komunikasi data DS340 dapat menggunakan interface serial RS-232 maupun paralel GPIB [8].

Standar primer frekuensi HP5071A memiliki akurasi dan stabilitas yang dibutuhkan untuk laboratorium kalibrasi maupun aplikasi di lapangan. Beam Tube pada standar cesium ini memiliki akurasi \pm 1 . $10^{-12} \mathrm{~Hz}$ dan kestabilan lingkungan $<1.10^{-13} \mathrm{~Hz}$ untuk perubahan frekuensi karena kondisi lingkungan. Jaminan ketepatan waktu karena laboratorium kalibrasi nasional masing-masing negara contohnya di

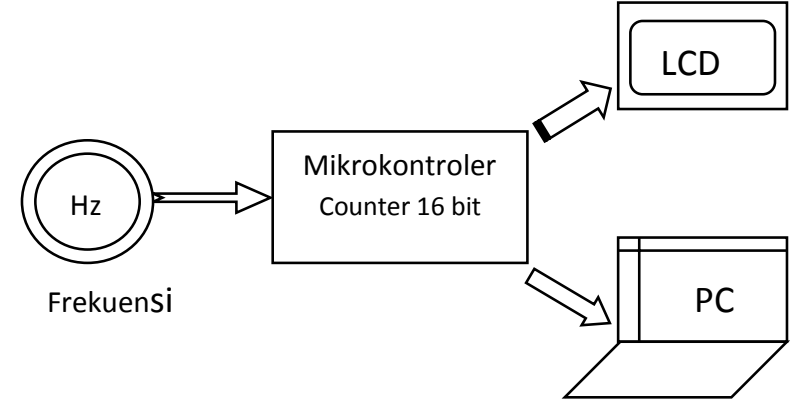

Gambar 5. Blok diagram rangkaian frekuensi meter

Indonesia oleh laboratorium waktu dan frekuensi Puslit Metrologi LIPI dapat memverifikasi stabilitas dan akurasi pengukuran waktu standar cesium pada Coordinated Universal Time (UTC), yang disediakan oleh Biro International des Poids et Mesures (BIPM) di Paris sebagai rujukan internasional. Akurasi dan keandalan standar ini sangat menentukan kualitas layanan ketepatan waktu pada laboratorium yang menggunakannya sehingga dapat memberikan layanan kalibrasi yang terpercaya kepada pelanggannya [9]. Standar jam atom cesium HP5071A di Puslit Metrologi LIPI ini menjadi acuan standar nasional pengukuran frekuensi di Indonesia.

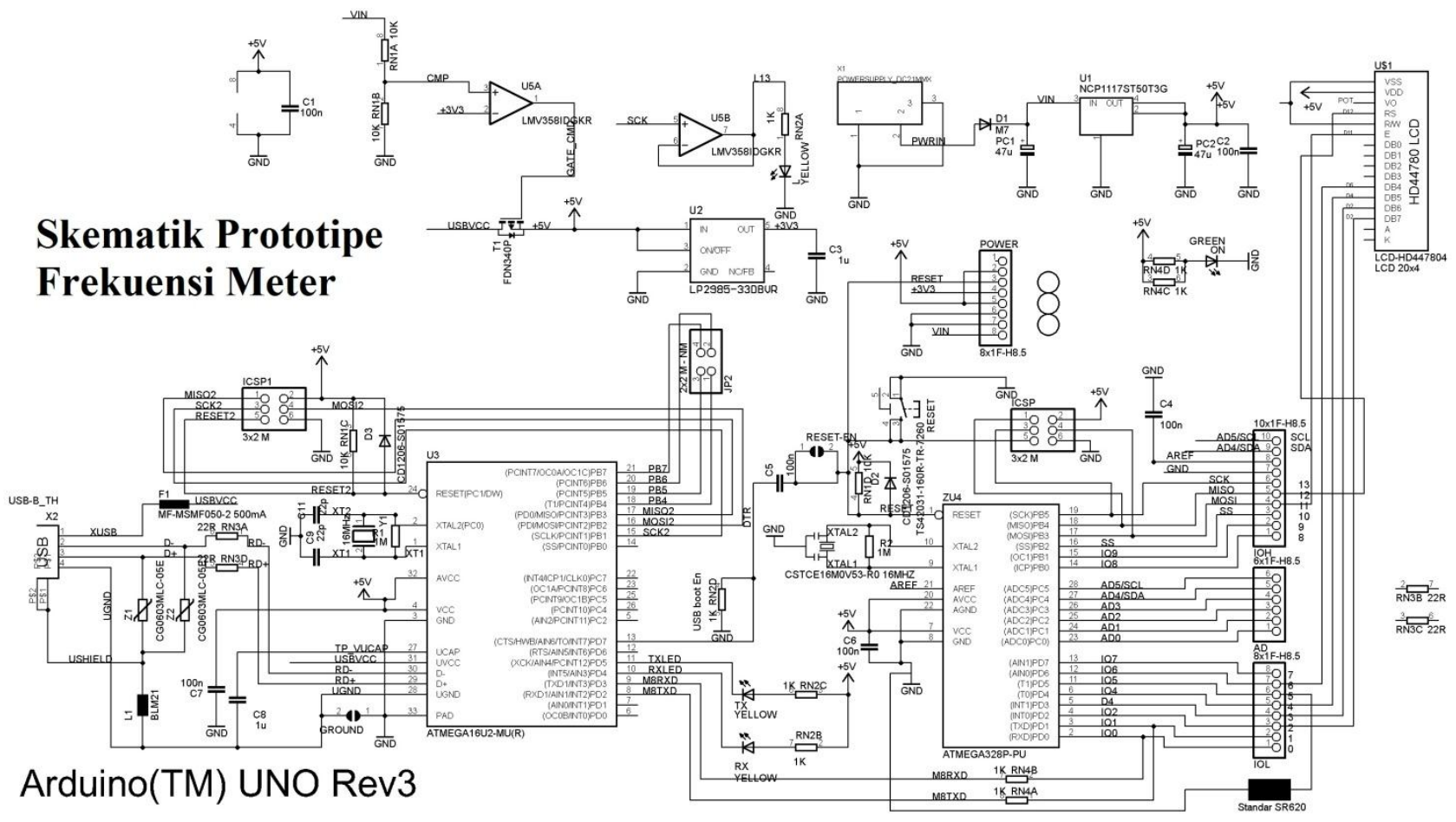

Gambar 6. Rangkaian elektronika prototipe frekuensi meter 


\section{Perancangan dan Pembuatan Rangkaian Prototipe Frekuensi Meter}

Mikrokontroler ATmega328 memiliki fasilitas counter resolusi tinggi sampai 65536 (16 bit) pada pin 5 digital Arduino Uno. Counter tersebut digunakan sebagai penghitung jumlah sinyal pulsa. Untuk mendapatkan data frekuensi dibutuhkan time base dari osilator sebesar 16 $\mathrm{MHz}$, melalui pengaturan register mikrokontroler pada pemrograman diperoleh time base sebesar 1 sekon. Kemudian mikrokontroler berkomunikasi ke Personal Computer (PC) secara serial melalui kabel USB. PC dapat menampilkan sekaligus mencatat data pada memorinya. Dalam rancangan ini, untuk mempermudah pemantauan maka data ditampilkan pula pada indikator LCD $20 \times 4$ karakter.

Dari blok diagram Gambar 5 tersebut dapat direalisasikan dalam bentuk rangkaian elektronika yang terlihat pada Gambar 6. Sebelum membuat program mikrokontroler, dibuat dahulu diagram alir rangkaian prototipe frekuensi meter untuk menggambarkan alur kerja sistem dan algoritma pemrograman mikrokontroler yang akan dibuat yang ditampilkan pada Gambar 7.

Dari blok digram tersebut kemudian diimplementasikan dalam pemrograman mikrokontroler menggunakan software open source Arduino yang dapat didownload pada alamat http://www.arduino.cc/en/Main/software. Pada software Aduino digunakan bahasa $\mathrm{C}$ untuk membuat program mikrokontroler. Software Aduino merupakan editor sekaligus uploader mikrokontroler. Setelah menuliskan program

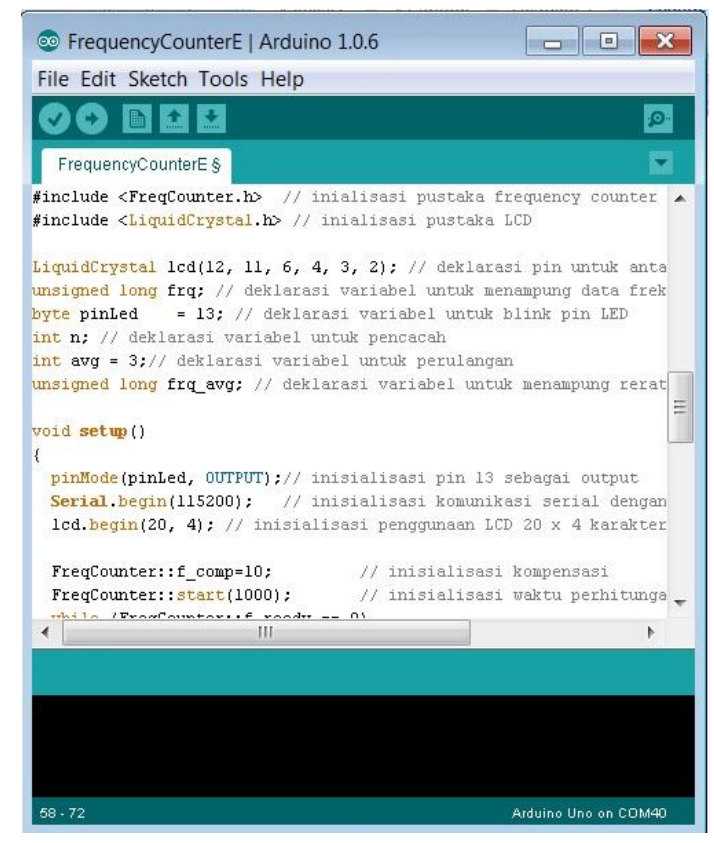

Gambar 8. Software Arduino dapat langsung di-compile dan di-upload ke mikrokontroler melalui kabel USB.

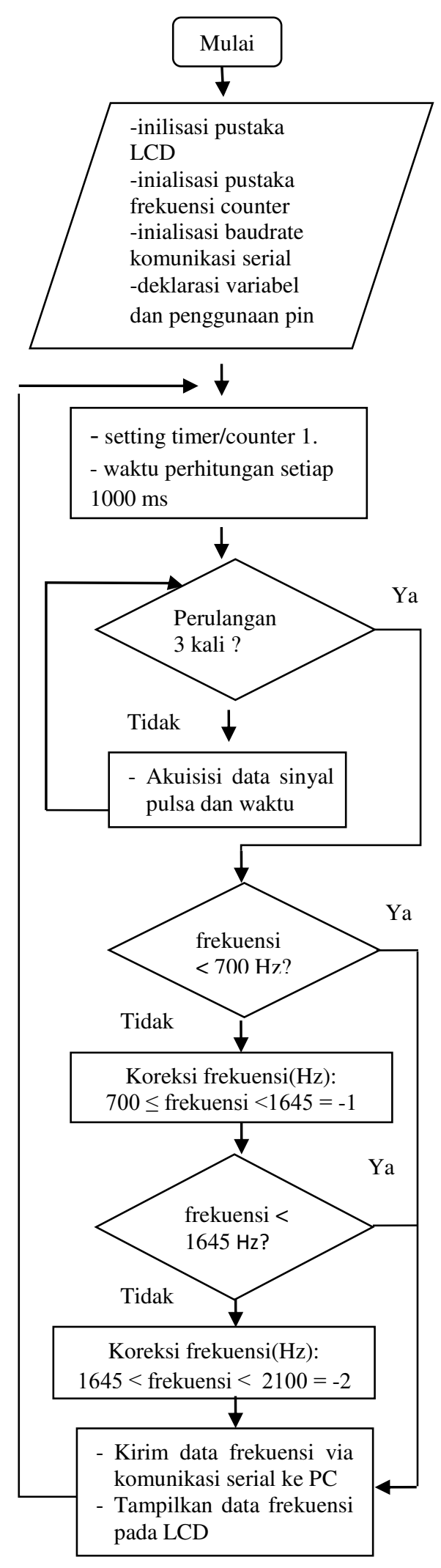

Gambar 7. Diagram Alir frekuensi meter 
Listing program hasil realisasi diagram alir prototipe frekuensi meter dapat dilihat di bawah ini :

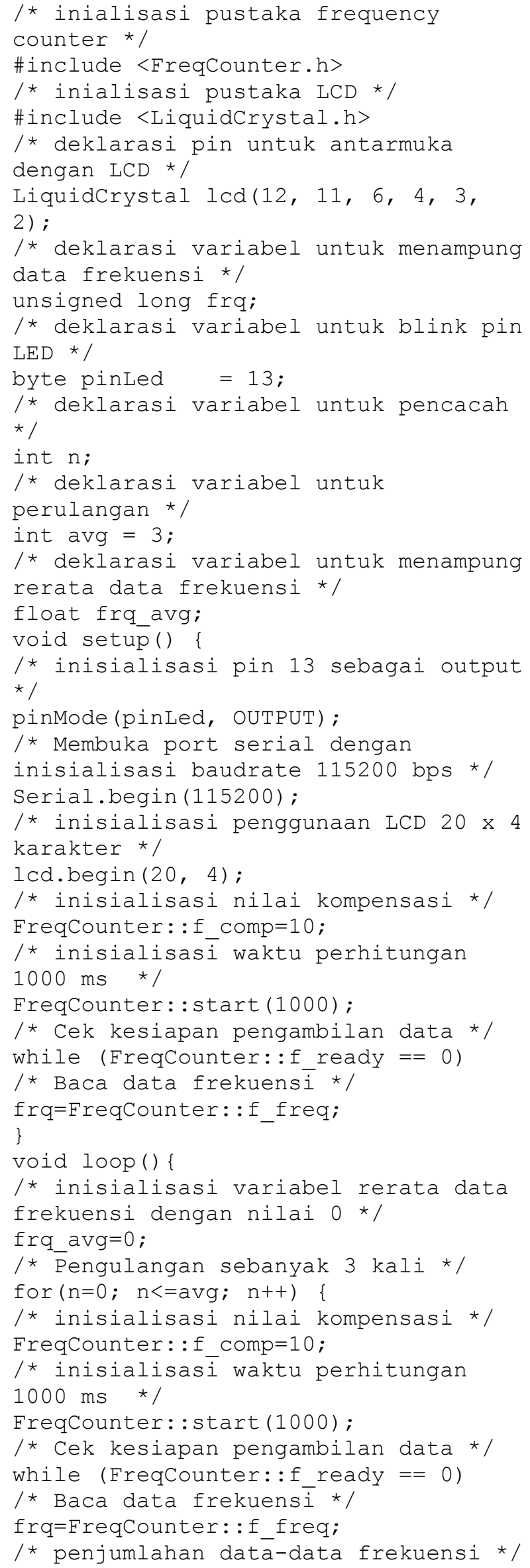

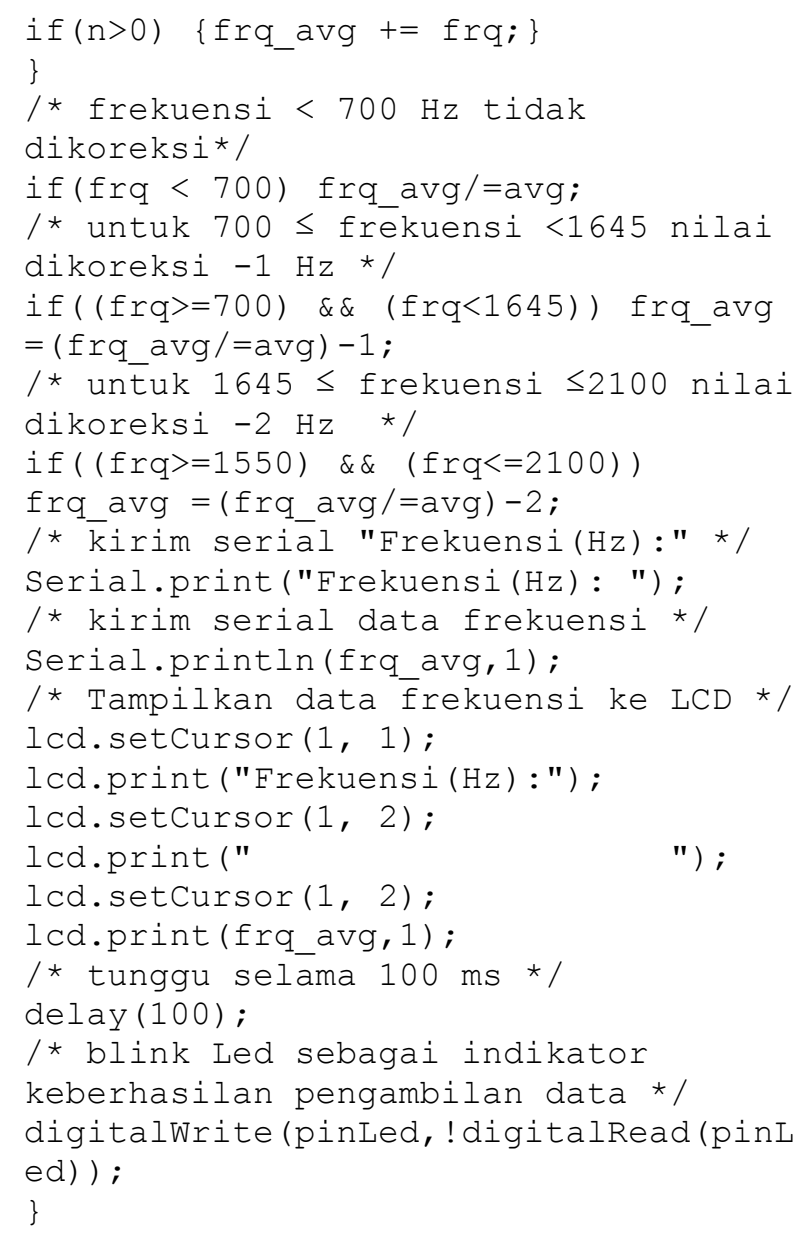

Gambar 9. Listing program

\subsection{Metode Pengukuran}

Tempat pengukuran dilakukan di laboratorium aliran Puslit Metrologi LIPI pada tanggal 23-26 Frebruari 2015 pada kondisi ruangan dengan temperatur $(23 \pm 2)^{\circ} \mathrm{C}$ dan kelembaban relatif (RH) $(55 \pm 5) \%$. Untuk mengkalibrasi prototipe ini digunakan metoda pengukuran frekuensi secara langsung (Direct Frequency Measurement) yaitu nilai frekuensi standar DS340 langsung dibandingkan dengan pembacaan Unit Under Test (UUT) prototipe frekuensi meter dengan acuan JCGM 100:2008 [7, 10, 11]. Kalibrasi dilakukan pada rentang ukur (10 2000) Hz. Jumlah sampel pengambilan data berjumlah 40 buah. Akuisisi data secara serial menggunakan software program aplikasi java untuk mempermudah pencatatan dan pengolahan data.

Berikut ini model matematis yang digunakan dalam mengkalibrasi prototipe frekuensi meter tersebut :

$$
\mathrm{f}_{\text {error }}=\mathrm{f}_{\mathrm{uut}}-\mathrm{f}_{\text {std }}
$$

Keterangan :

$\mathrm{F}_{\text {error }}=$ Koreksi pembacaan frekuensi, $\mathrm{Hz}$

$\mathrm{f}_{\text {std }} \quad=$ Pembacaan frekuensi pada standar 
DS340, $\mathrm{Hz}$

$\mathrm{f}_{\text {uut }} \quad=$ Pembacaan frekuensi pada unit under test prototipe frekuensi meter, $\mathrm{Hz}$

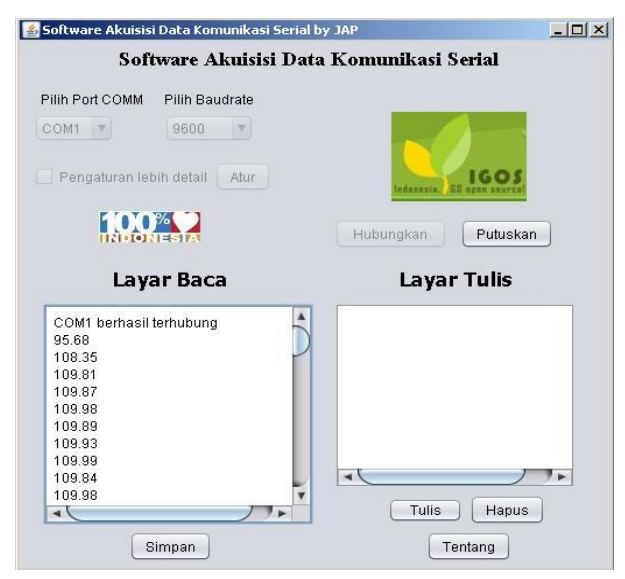

Gambar 10. Program aplikasi java

Sumber-sumber ketidakpastian yang diperhitungkan berasal dari ketertelusuran standar DS340 serta resolusi dan repeatability dari standar dan prototipe frekuensi meter sedangkan sumber ketidakpastian lainnya diabaikan dalam perhitungan. Untuk evaluasi ketidakpastian pengukuran data tipe $\mathrm{A}$ dan $\mathrm{B}$ dihitung dengan perumusan berikut ini $[11,12]$ :

$$
\begin{aligned}
\bar{x} & =\frac{\sum x_{i}}{n} \\
\mathrm{u}_{\mathrm{i}}=\frac{s}{\sqrt{n}} & =\frac{\sqrt{\frac{\sum\left(x_{i}-\bar{x}\right)^{2}}{n-1}}}{\sqrt{n}} \\
\mathrm{v}_{\mathrm{i}} & =\mathrm{n}-1 \\
\mathrm{u}_{\mathrm{i}} & =\frac{a_{i}}{D}=1 / 2 \cdot \frac{r e s}{\sqrt{3}} \\
\mathrm{v}_{\mathrm{i}} & \left.=1 / 2 \cdot \frac{100}{R}\right)^{2} \\
c i & =\frac{\partial F(x)}{\partial x} \\
\mathrm{u}_{\mathrm{c}} & =\sqrt{\sum c_{i}{ }^{2} \cdot u_{i}{ }^{2}} \\
\mathrm{v}_{\mathrm{eff}} & =\frac{u_{c}{ }^{4}}{\sum \frac{c_{i}{ }^{4} \cdot u_{i}{ }^{4}}{v_{i}}} \\
\mathrm{U}_{\mathrm{ex}} & =\mathrm{k} \cdot \mathrm{u}_{\mathrm{c}} \\
\varepsilon & =\left|\mathrm{f}_{\text {error }}\right|+\mathrm{U}_{\mathrm{ex}}
\end{aligned}
$$

dimana:

$\mathrm{u}_{\mathrm{i}}=$ Ketidakpastian baku data ke-i pengukuran $\mathrm{u}_{\mathrm{c}}=$ Ketidakpastian gabungan pengukuran

$\mathrm{s}$ = Nilai simpangan baku atau standar deviasi

$\mathrm{x}_{\mathrm{i}}=$ Nilai data ke- $\mathrm{i}$

$\bar{x}=$ Nilai rata-rata

$\mathrm{n}=$ Jumlah data

$\mathrm{a}=$ Rentang paruh

res $=$ Resolusi alat ukur

$\mathrm{D}=$ Distribusi/ sebaran

$\mathrm{R}=$ Tingkat keraguan

$\mathrm{c}_{\mathrm{i}}=$ Koefisien sensitivitas data ke- $\mathrm{i}$

$\mathrm{F}(\mathrm{x})=$ Model matematis

$\mathrm{v}_{\mathrm{i}}=$ Derajat kebebasan data ke-i pengukuran

$\mathrm{v}_{\text {eff }}=$ Derajat kebebasan efektif pengukuran

$\mathrm{k}=$ Faktor cakupan sesuai faktor-t student

$\mathrm{U}_{\mathrm{ex}}=$ Ketidakpastian terentang

$\mathcal{E}=$ Kemungkinan error terbesar

\section{Hasil dan Analisa Data}

Kalibrasi prototipe frekuensi meter dilakukan pada rentang ukur $10 \sim 2000 \mathrm{~Hz}$ dengan 37 jumlah titik ukur. Perencanaan selang titik ukur / span tiap $100 \mathrm{~Hz}$ dan titik ukur lainnya yang ingin diketahui sesuai kebutuhan pemakaian pada pengukur turbin sehingga keseluruhan titik ukur berjumlah 37 titik. Pengulangan pengambilan data sebanyak 40 kali untuk tiap masing-masing titik ukur agar memperbanyak derajat kebabasan dan lebih dapat mendekati nilai sebenarnya sesuai sebaran statistik student- $t$ [11].

Pada pemrograman mikrokontroler dilakukan uji coba penyaringan dan perata-rataan dalam proses pengambilan data. Berikut ini hasil pengukuran awal uji coba penyaringan dan peratarataan pengambilan data frekuensi pada manipulasi pemrograman mikrokontroler dengan jumlah pengulangan (n) kali yang ditampilkan pada Tabel 1.

Dari hasil pengukuran penyaringan dan peratarataan pengambilan data pada pemrograman mikrokontroler pada Tabel 1, jumlah pengulangan(n) sebanyak 3 kali pengambilan data memiliki nilai optimal terbaik yaitu rerata error dan jumlah pengulangan paling kecil. Respone time akan sebanding dengan jumlah pengulangan tersebut. Oleh karena itu pada diagram alir pada Gambar 7 dan listing program pada Gambar 9, dilakukan tambahan algoritma perhitungan rerata dari 3 kali pengulangan dan proses pencocokan koreksi pada frekuensi di atas $700 \mathrm{~Hz}$ agar hasilnya lebih akurat mendekati nilai kalibrator. 
Tabel 1. Hasil pengukuran penyaringan dan peratarataan pengambilan data pada pemrograman mikrokontroler

\begin{tabular}{cccc}
\hline $\begin{array}{c}\text { Frekuensi } \\
\text { standar } \\
(\mathrm{Hz})\end{array}$ & $\begin{array}{c}\mathrm{n}=1 \\
\text { Error } \\
(\mathrm{Hz})\end{array}$ & $\begin{array}{c}\mathrm{n}=3 \\
\text { Error } \\
(\mathrm{Hz})\end{array}$ & $\begin{array}{c}\mathrm{n}=5 \\
\text { Error } \\
(\mathrm{Hz})\end{array}$ \\
\hline 7020 & 1 & 1 & 1 \\
\hline 800 & 1 & 1 & 1 \\
\hline 900 & 1 & 1 & 1 \\
\hline 1000 & 1 & 1 & 1 \\
\hline 1100 & 1 & 1 & 1 \\
\hline 1200 & 1 & 1 & 1 \\
\hline 1300 & 2 & 1 & 1 \\
\hline 1400 & 2 & 1 & 1 \\
\hline 1500 & 2 & 1 & 1 \\
\hline 1550 & 2 & 1 & 1 \\
\hline 1600 & 2 & 1 & 1 \\
\hline 1700 & 2 & 2 & 2 \\
\hline 1800 & 2 & 2 & 2 \\
\hline 1900 & 2 & 2 & 2 \\
\hline 2000 & 3 & 2 & 2 \\
\hline Rerata & 1,7 & 1,2 & 1,2 \\
\hline & & &
\end{tabular}

Berikut ini hasil kalibrasi prototipe frekuensi meter dengan kalibrator standar DS340 setelah proses pencocokan koreksi dengan jumlah pengulangan pengambilan data sebanyak 40 kali untuk setiap titik ukur yang ditampilkan pada tabel 2 dan Gambar 11.

Tabel 2. Hasil kalibrasi prototipe frekuensi meter

\begin{tabular}{|c|c|c|c|c|}
\hline $\begin{array}{c}\mathrm{f}_{\text {std }} \\
(\mathrm{Hz}) \\
\end{array}$ & $\begin{array}{c}\mathrm{f}_{\text {uut }} \\
(\mathrm{Hz})\end{array}$ & $\begin{array}{l}\mathrm{f}_{\text {error }} \\
(\mathrm{Hz})\end{array}$ & $\begin{array}{c}\mathrm{U}_{\mathrm{ex}} \\
(\mathrm{Hz}) \\
\end{array}$ & $\begin{array}{c}\varepsilon \\
(\mathrm{Hz}) \\
\end{array}$ \\
\hline 10,0 & 10,0 & 0,0 & 0,060 & 0,07 \\
\hline 18,6 & 18,6 & 0,0 & 0,073 & 0,11 \\
\hline 33,3 & 33,3 & 0,0 & 0,058 & 0,06 \\
\hline 40,0 & 40,0 & 0,0 & 0,066 & 0,10 \\
\hline 63,5 & 63,6 & 0,1 & 0,083 & 0,15 \\
\hline 86,4 & 86,5 & 0,1 & 0,085 & 0,17 \\
\hline 100,0 & 100,1 & 0,1 & 0,073 & 0,17 \\
\hline 145,0 & 145,0 & 0,0 & 0,066 & 0,10 \\
\hline 200,0 & 200,2 & 0,2 & 0,075 & 0,23 \\
\hline 300,0 & 300,3 & 0,3 & 0,067 & 0,32 \\
\hline 333,1 & 333,4 & 0,3 & 0,083 & 0,39 \\
\hline 400,0 & 400,4 & 0,4 & 0,080 & 0,48 \\
\hline 468,2 & 468,7 & 0,5 & 0,066 & 0,55 \\
\hline 500,0 & 500,5 & 0,5 & 0,086 & 0,59 \\
\hline 600,0 & 600,6 & 0,6 & 0,082 & 0,66 \\
\hline 655,6 & 656,2 & 0,6 & 0,071 & 0,70 \\
\hline 700,0 & 699,7 & $-0,3$ & 0,086 & 0,38 \\
\hline 777,8 & 777,6 & $-0,2$ & 0,075 & 0,25 \\
\hline 800,0 & 799,8 & $-0,2$ & 0,073 & 0,27 \\
\hline 900,0 & 899,9 & $-0,1$ & 0,073 & 0,18 \\
\hline 986,9 & 986,9 & 0,0 & 0,070 & 0,10 \\
\hline 1000,0 & 1000,0 & 0,0 & 0,074 & 0,09 \\
\hline 1100,0 & 1100,1 & 0,1 & 0,082 & 0,15 \\
\hline 1200,0 & 1200,2 & 0,2 & 0,075 & 0,23 \\
\hline 1300,0 & 1300,2 & 0,2 & 0,071 & 0,30 \\
\hline
\end{tabular}

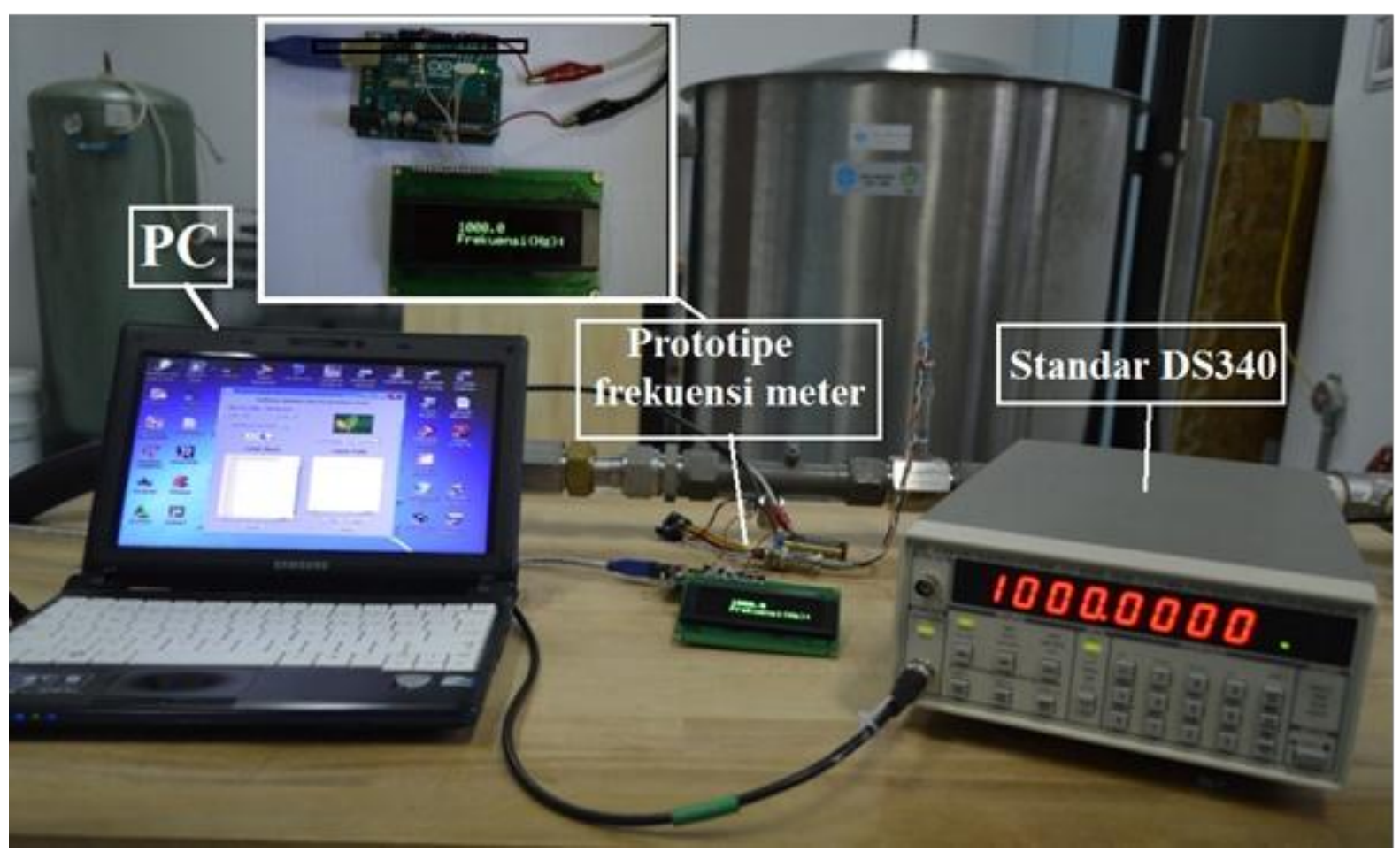

Gambar 11. Kalibrasi Prototipe frekuensi meter dengan standar DS340 


\begin{tabular}{rrrrr}
\hline 1333,3 & 1333,6 & 0,3 & 0,077 & 0,40 \\
\hline 1400,0 & 1400,4 & 0,4 & 0,10 & 0,47 \\
\hline 1500,0 & 1500,4 & 0,4 & 0,093 & 0,53 \\
\hline 1573,7 & 1574,2 & 0,5 & 0,073 & 0,58 \\
\hline 1600,0 & 1600,6 & 0,6 & 0,082 & 0,66 \\
\hline 1645,0 & 1644,6 & $-0,4$ & 0,080 & 0,48 \\
\hline 1700,0 & 1699,7 & $-0,3$ & 0,096 & 0,41 \\
\hline 1800,0 & 1799,8 & $-0,2$ & 0,094 & 0,34 \\
\hline 1818,3 & 1818,0 & $-0,3$ & 0,11 & 0,37 \\
\hline 1900,0 & 1899,9 & $-0,1$ & 0,074 & 0,19 \\
\hline 1991,5 & 1991,4 & $-0,1$ & 0,082 & 0,16 \\
\hline 2000,0 & 2000,0 & 0,0 & 0,084 & 0,11 \\
\hline
\end{tabular}

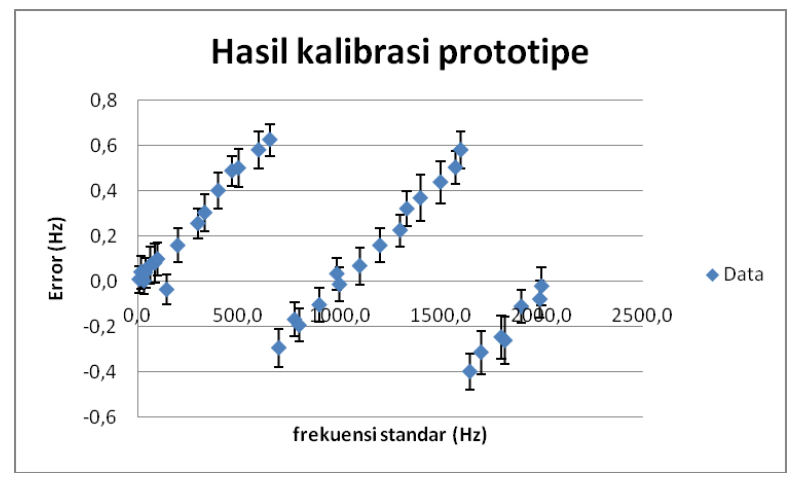

Gambar 12. Hasil kalibrasi prototipe frekuensi meter dengan standar DS340

Terlihat pada Tabel 2 dan Gambar 12, titik ukur $33,3 \mathrm{~Hz}$ memiliki error, ketidakpastian dan kemungkinan error terbesar dengan nilai paling kecil yaitu error sebesar $(0,00 \pm 0,058) \mathrm{Hz}$ dengan kemungkinan error terbesar $0,06 \mathrm{~Hz}$. Sedangkan error terbesar terdapat pada titik ukur $1600,0 \mathrm{~Hz}$ yaitu sebesar $0,6 \mathrm{~Hz}$ dan ketidakpastian terbesar terdapat pada titik ukur $1818,3 \mathrm{~Hz}$ yaitu sebesar 0,11 Hz. Nilai kemungkinan error terbesar terdapat pada titik ukur $655,6 \mathrm{~Hz}$ yaitu sebanyak $0,7 \mathrm{~Hz}$ sehingga prototipe ini memiliki akurasi relatif untuk skala penuh kapasitas $2000 \mathrm{~Hz}$ sebesar $0,03 \%$.

Error dan ketidakpastian tersebut kemungkinan besar diakibatkan dari akurasi dari clock $16 \mathrm{MHz}$ dan counter mikrokontroler yang digunakan. Ketidak benar-benar sinkron dan perbedaan perubahan waktu antara clock mikrokontroler dengan clock pada atom cesium133 standar primer HP-5071A membuat kesalahan tersebut. Keterbatasan resolusi mikrokontroler dalam membaca sinyal pulsa juga dapat mengakibatkan kesalahan tersebut. Hal itu tergambarkan pada grafik Gambar 12. Namun akurasi prototipe frekuensi meter tersebut dengan nilai $0,03 \%$ sudah sangat baik untuk memenuhi kebutuhan data akuisisi untuk sinyal pulsa pada pengukur aliran jenis turbin yang memerlukan akurasi $0,05 \%$, [2]. Berikut ini diagram ketertelusuran pengukuran prototipe frekuensi meter yang terbangun ke satuan SI demi menjamin kebenarannya secara internasional.

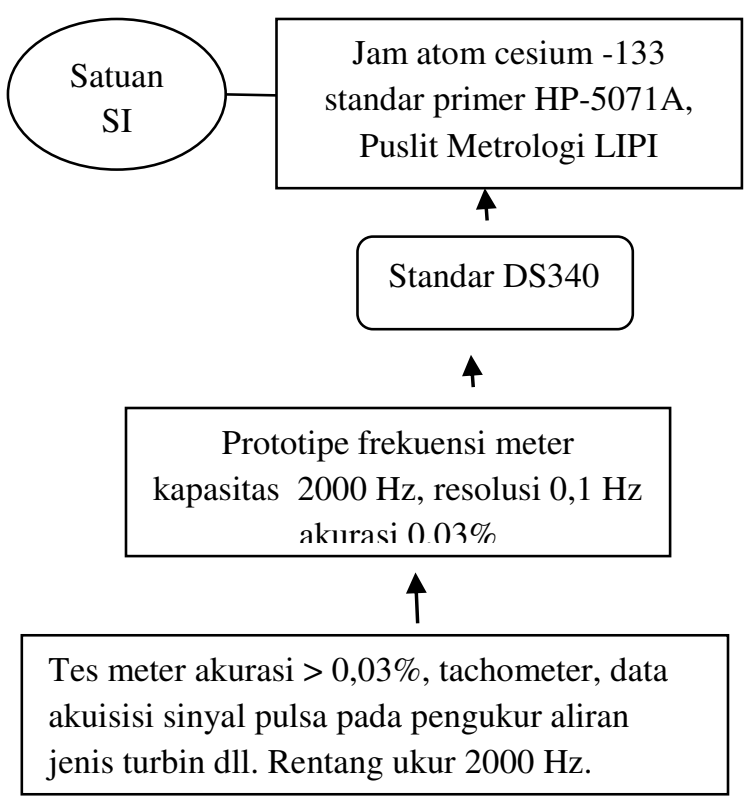

Gambar 13. Diagram ketertelusuran pengukuran prototipe frekuensi meter

\section{Kesimpulan}

Dari hasil pengukuran awal pada rentang ukur 10 2000 Hz, diketahui terdapat error yang signifikan pada titik ukur $700 \mathrm{~Hz}$ ke atas. Jumlah pengulangan(n) sebanyak 3 kali pengambilan data memiliki nilai optimal terbaik yaitu rerata error dan jumlah pengulangan paling kecil dibanding pengulangan sebanyak 1 dan 5 kali. Dapat dilakukan proses pencocokan koreksi pada frekuensi di atas $700 \mathrm{~Hz}$ pada algoritma pemrograman Arduino agar hasilnya lebih akurat mendekati nilai standar.

Dari hasil pengukuran setelah proses pencocokan koreksi pada rentang ukur 10 2000 $\mathrm{Hz}$ didapatkan bahwa titik ukur $33,3 \mathrm{~Hz}$ memiliki error, ketidakpastian dan kemungkinan error terbesar dengan nilai paling kecil yaitu error sebesar $(0,00 \pm 0,058) \mathrm{Hz}$ dengan kemungkinan error terbesar $0,06 \mathrm{~Hz}$. Sedangkan error terbesar terdapat pada titik ukur $1600,0 \mathrm{~Hz}$ yaitu sebesar $0,6 \mathrm{~Hz}$ dan ketidakpastian terbesar terdapat pada titik ukur $1818,3 \mathrm{~Hz}$ yaitu sebesar $0,11 \mathrm{~Hz}$. Nilai kemungkinan error terbesar terdapat pada titik ukur $655,6 \mathrm{~Hz}$ yaitu sebanyak $0,7 \mathrm{~Hz}$. kesalahan tersebut kemungkinan besar diakibatkan dari keterbatasan akurasi dari clock $16 \mathrm{MHz}$ dan 
counter pada mikrokontroler dibandingkan clock pada atom cesium-133 standar primer HP-5071A. Telah berhasil dibangun ketertelusuran pengukuran prototipe frekuensi meter kapasitas $2000 \mathrm{~Hz}$ dan resolusi $0,1 \mathrm{~Hz}$ tersebut dengan akurasi $0,03 \%$ relatif skala penuh yang telah sangat baik dapat memenuhi kebutuhan data akuisisi untuk sinyal pulsa pada pengukur aliran jenis turbin.

\section{Ucapan Terima Kasih}

Penulis mengucapkan terima kasih kepada Martin Nawrath dari Lab3 Laboratory for Experimental Computer Science at the Academy of Media Arts Cologne yang telah berbagi pustaka frequency counter untuk pemrograman open source Arduino.

Terima kasih pula kepada manajemen Puslit Metrologi LIPI yang telah menyediakan fasilitas standar primer frekuensi cesium HP-5071A sehingga kegiatan penelitian ini dapat berlangsung.

\section{Daftar Pustaka}

[1] Balbuena, Daniel Hernández., Oleg Sergiyenko, Vera Tyrsa, Larysa Burtseva, Moisés Rivas López. 2008. "Signal frequency measurement by rational approximations". Journal of Measurement, vol 42, hal.136-144, 2009.

[2] Flow Technology Incorporated. FT SERIES TURBINE FLOWMETERS Installation, Operation and Maintenance Manual. Arizona: FTI, 2006.

[3] Bureau International des Poids et Mesures. The International System of Units (SI) 8th edition. Paris : Organisation Intergouvernementale de la Convention du Mètre, 2006.

[4] Arduino, Arduino Uno, (http://arduino.cc/en/Main/arduinoBoardUno, diakses 20 Februari 2015)

[5] Atmel Corporation. 8-bit AVR Microcontroller with 4/8/16/32K Bytes In-System Programmable Flash ATmega48PA ATmega88PA ATmegal68PA ATmega328P Rev. 8161D-AVR-10/09. USA : Atmel. 2009.

[6] Michael A. Lombardi. NIST Frequency Measurement and analysis System: Operator's Manual. USA:NIST. 2001.

[7] Badan Standarisasi Nasional. 2008. Persyaratan umum kompetensi laboratorium pengujian dan laboratorium kalibrasi SNI ISO/IEC 17025:2008. Jakarta:BSN.

[8] Stanford Research Systems. Synthesized Function Generators $D S 340-15 \mathrm{MHz}$ function and arbitrary waveform generator. California: SRS. 2006.

[9] Agilent Tehnologies. Agilent 5071A Primary Frequency Standard Unsurpassed Stability in the Lab or Field. USA : Agilent. 2000.
[10]Ratnaningsih dan Boynawan A.M. "Kalibrasi Frekuensi Menggunakan Metoda Pengukuran Langsung (Direct Measurement)". Pertemuan dan Presentasi Ilmiah (PPI) KIM Tahun 2011. Tangerang: Pusat Penelitian Kalibrasi, Instrumentasi dan Metrologi LIPI. 2011.

[11]JCGM, "Evaluation of measurement data Guide to the expression of uncertainty in measurement". . JCGM 100:2008, Paris: BIPM, IEC, IFCC, ILAC, ISO, IUPAC, IUPAP dan OIML.

[12] Siraya, T.N. "Comparison Of Uncertainty Estimates: Allan Variance And Sample Variance”. Journal Measurement Science Review, vol. 1, no. $1,2001$. 